\title{
Evaluation of data loggers, sampling intervals, and editing techniques for measuring the lying behavior of dairy cattle
}

\author{
D. N. Ledgerwood, ${ }^{*}$ C. Winckler, $†$ and C. B. Tucker ${ }^{* 1}$ \\ *Department of Animal Science, University of California, Davis 95616 \\ †Department of Sustainable Agricultural Systems, University of Natural Resources and Life Sciences Vienna (BOKU), Gregor Mendel-Strasse 33, \\ 1180 Vienna, Austria
}

\section{ABSTRACT}

Lying behavior in dairy cattle can provide insight into how cows interact with their environment. Although lying behavior is a useful indicator of cow comfort, it can be time consuming to measure. In response to these time constraints, using data loggers to automate behavioral recording has become increasingly common. We tested the accuracy of the Onset Pendant G data logger (Onset Computer Corporation, Bourne, MA) for measuring lying behavior in dairy cattle $(\mathrm{n}=24$ cows; 12 in each of 2 experiments). Cows wore the logger on the lateral (experiment 1) or medial (experiment 2) side of the hind leg above the metatarsophalangeal joint. Loggers recorded behavior at 4 sampling intervals $(6,30,60$, and $300 \mathrm{~s})$ for at least $1.5 \mathrm{~d}$. Data were smoothed using 3 editing methods to examine the effects of short, potentially erroneous readings. For this purpose, Microsoft Excel macros (Microsoft Corp., Redmond, WA) converted readings (i.e., lying events bordered by standing or vice versa) occurring singly or in consecutive runs of $\leq 2$ or $\leq 6$. Behavior was simultaneously recorded with digital video equipment. The logger accurately measured lying and standing. For example, predictability, sensitivity, and specificity were $>99 \%$ using 30-s sampling and the single-event filter compared with continuously scored video recordings. The 6- and 30-s sampling intervals were comparable for all aspects of lying behavior when short events were filtered from the data set. Estimates of lying time generated from the 300-s interval unfiltered regimen were positively related $\left(R^{2} \geq 0.99\right)$ to estimates of lying time from video, but this sampling regimen overestimated the number of lying bouts. This is likely because short standing and lying bouts were missed (12 and $34 \%$ of lying and standing bouts were $<300 \mathrm{~s}$ in experiment 1 and 2 , respectively). In summary, the data logger accurately measured all aspects of lying behavior when the

Received November 24, 2009.

Accepted July 8, 2010.

${ }^{1}$ Corresponding author: cbtucker@ucdavis.edu sampling interval was $\leq 30 \mathrm{~s}$ and when short readings of lying and standing were filtered from the data set.

Key words: lying, behavior, automated measurement, validation

\section{INTRODUCTION}

Several recent studies provide insight into how housing design and management affect lying behavior. For example, cows spent more time lying down in tie-stalls fitted with mattresses compared with stalls with concrete floors (increase of $1.8 \mathrm{~h} / 24 \mathrm{~h}$; Haley et al., 2001) and in stalls with dry bedding compared with stalls with wet bedding (increase of $4.9 \mathrm{~h} / 24 \mathrm{~h}$; Fregonesi et al., 2007). In addition to total lying time, other aspects of lying behavior are affected by housing design and management; these responses can provide insight into why behavioral changes occur. For example, cows respond to poorly bedded stalls by lying down less often (Tucker and Weary, 2004), perhaps because of the considerable weight placed on the carpal joint during the transition from standing to lying. In contrast, cows with claw injuries (Chapinal et al., 2009) and those in narrower freestalls (Tucker et al., 2004a) remain lying down for longer, likely because of discomfort when rising or when touching freestall partitions, respectively.

In addition to the structure of lying bouts, considerable variation exists in the laterality of lying behavior (Tucker et al., 2009). Pronounced laterality may indicate that cows are uncomfortable; cows with a rumen cannula and cows late in pregnancy show marked laterality while lying, perhaps because of discomfort associated with the cannula or the calf (Arave and Walters, 1980; Grant et al., 1990; Forsberg et al., 2008). Thus, lying behaviors, including total lying time, number of lying bouts, average bout duration, and laterality of lying behavior, collectively improve our understanding of the mechanism underlying changes in cow comfort.

Despite the insights gained through these behavioral indicators of cow comfort, measuring lying behavior in cattle using direct or video-based observations is time consuming. Automated recording devices have become increasingly common to overcome this limita- 
tion. Several commercially available data loggers record lying behavior in cattle. Loggers are attached around the neck (Watanabe et al., 2008; Martiskainen et al., 2009), body (Champion et al., 1997), or leg (Müller and Schrader, 2003; McGowan et al., 2007; O'Driscoll et al., 2008; White et al., 2008; Darr and Epperson, 2009; Robert et al., 2009; Trénel et al., 2009). Loggers used on the leg generally provide more accurate measures of lying behavior than those attached around the neck [e.g., $80 \%$ correct classification of lying when attached to the neck vs. $100 \%$ correct classification of lying when attached to the leg in Martiskainen et al. (2009) and Trénel et al. (2009), respectively] and are more common than those attached around the body. Loggers attached to the leg vary in size and weight (Table 1), and all but one (Tinytag, Gemini Data Loggers, Chichester, UK) use an accelerometer to assess behavior. These loggers are able to measure lying time but are less accurate when assessing other behaviors such as activity (Müller and Schrader, 2003; McGowan et al., 2007; White et al., 2008; Robert et al., 2009; Trénel et al., 2009) unless the sampling interval is extremely short (every $10 \mathrm{~ms}$; Scheibe and Gromann, 2006). Two models of leg loggers accurately assessed the number of lying bouts (McGowan et al., 2007; Darr and Epperson, 2009; Trénel et al., 2009), but the sample sizes of these studies were small (15 and 17 lying bouts or only 5 calves monitored for $12 \mathrm{~h}$ ). To date, laterality of lying behavior has not been measured with any logger.

Several methodological issues, including sampling and editing regimens, remain unresolved with these leg loggers. The sampling intervals used to estimate lying behavior over days or weeks ranged from multiple readings every second (Scheibe and Gromann, 2006; Trénel et al., 2009) to every $10 \mathrm{~min}$ (Müller and Schrader, 2003). All of these sampling intervals are likely suitable for assessing lying time (Mitlöhner et al., 2001), but it is unclear which regimen is appropriate for describing changes in behavior (e.g., between lying down or standing up) that occur relatively quickly and infrequently. Some authors exclude these transitions altogether (Robert et al., 2009), raising questions about repeatable editing of logger output between studies. O'Driscoll (2008) found that removing short, possibly erroneous recordings improved the estimate of time spent lying, whereas others have described case-by-case modification of data (Müller and Schrader, 2003). Thus, systematic evaluation of such data editing is needed to establish a reliable methodology for measuring lying behavior using data loggers.

Our objectives were 3 -fold: 1) to evaluate the accuracy of the Onset Pendant G data logger (Onset Computer Corporation, Bourne, MA) when measuring lying behavior (lying on the left side, lying on the right

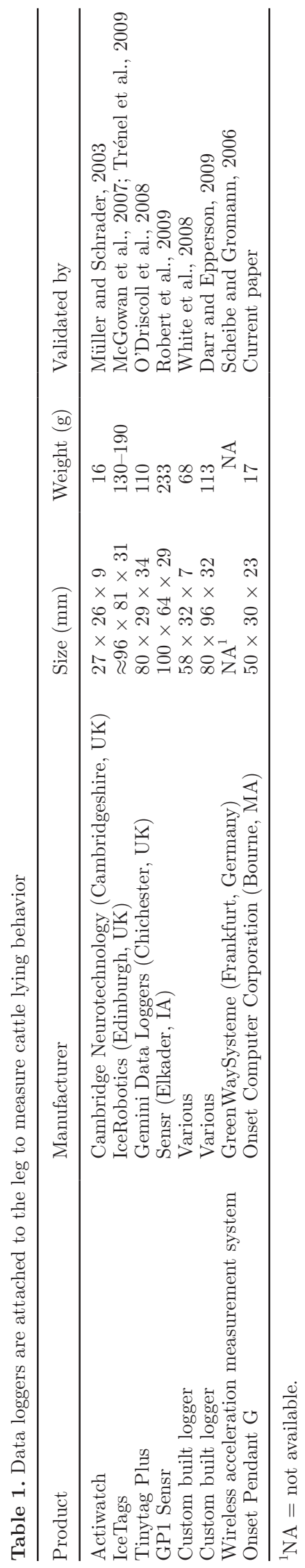


side, total lying time, and number of lying bouts), 2) to evaluate 4 sampling intervals $(6,30,60$, and $300 \mathrm{~s})$, and 3 ) to evaluate the effect of removing short, possibly erroneous standing and lying readings from the raw data sets. These objectives were achieved with 2 experiments that differed in several ways, representing a range of test conditions under which the logger might be used.

\section{MATERIALS AND METHODS}

These experiments were approved by the University of California Davis Animal Use and Care Committee. All values in this section are reported as mean \pm standard deviation.

\section{Experiment 1}

Animals. This study was conducted during the fall (October and November 2007) at the University of California Davis dairy farm (Davis). Twelve lactating cows (11 Holstein-Friesian and 1 Jersey) were divided into 2 groups of 6 and were part of another study. Each group of cows was housed within a larger group of 24 animals (as described by Grubmüller, 2008).

Cows weighed $508 \pm 80 \mathrm{~kg}$, were $44 \pm 14$ mo of age, and had a BCS of $3.0 \pm 0.4$ on a scale of 1 to 5 (Ferguson et al., 1994). Ten cows were pregnant (17 $\pm 10 \mathrm{wk})$. The cows were housed in a pen with 2 uncovered areas $(9 \mathrm{~m} \times 20 \mathrm{~m}$ and $18 \mathrm{~m} \times 20 \mathrm{~m})$ and 1 covered area $(8 \mathrm{~m}$ $\times 20 \mathrm{~m})$. The covered area contained 24 head-to-head freestalls $(1.2 \mathrm{~m} \times 2.4 \mathrm{~m} ; 1 \mathrm{cow} /$ freestall $)$ deep-bedded with sand and with a neck rail located at $106 \pm 2 \mathrm{~cm}$ above the stall surface. Cows had ad libitum access to water and were fed a TMR consisting of $37 \%$ alfalfa hay, $36 \%$ grain mix, $10 \%$ whole cottonseed, $12 \%$ almond hulls, $2 \%$ soybean meal, and $3 \%$ mineral mix on a DM basis. They were fed 3 times daily at 0400, 1100, and $1600 \mathrm{~h}$. The cows were removed from the pen and milked twice daily $(0.5 \pm 0.2 \mathrm{~h} /$ milking$)$.

Behavioral Recordings. Lying and standing times were recorded continuously with WV-BP334 black and white CCTV video cameras (Panasonic Corporation of North America, Secaucus, NJ) and 13VG2812ASII lenses (Tamron, Commack, NY) connected to a digital video recorder with a GV-1120/1240/1480 combo card (USA Vision Systems Inc., Irvine, CA) and IPD-NVR16 digital surveillance software (Clearvision Inc., Wheeling, IL). Eight cameras and 4 red lights were positioned 2.4 and $3.0 \mathrm{~m}$, respectively, above the freestalls. Two additional cameras were used to record the uncovered areas in the pen. Each camera was set to continuously record at medium quality and 30 frames/s. Individual cows were identified by markings made with hair dye. Onset Pendant G data loggers (64k, Onset Computer
Corporation, Bourne, MA) were set to record the $\mathrm{x}, \mathrm{y}$, and z-axis at a 6 -s interval until the memory storage in the data loggers was full (i.e., approximately $1.5 \mathrm{~d}$ ). A trained individual (D.N. Ledgerwood) watched the video continuously and recorded the time in which a lying event began (when the flank of the cow contacted the ground), the side of each lying event (left, right), and the end of the lying event (when all 4 legs were perpendicular to the ground). This individual had an intraobserver reliability of $97.4 \%$ agreement for total lying time, time lying on the left side, and number of lying bouts for a subset of the data set $(n=8$ cows for $9 \mathrm{~h}$ ). Agreement was calculated as a correlation in Microsoft Excel (Microsoft Corp., Redmond, WA).

\section{Experiment 2}

Animals. This study was conducted during the summer (July to August 2008) at the University of California Davis Cole facility (Davis). Four nonlactating pregnant Holstein-Friesian cows and 8 pregnant Holstein-Friesian heifers were divided into 3 groups (n $=4$ cows (group).

The animals weighed $662 \pm 105 \mathrm{~kg}$, were $26 \pm 12$ mo of age, and had a BCS of $3.7 \pm 0.1$ on a scale of 1 to 5 (Ferguson et al., 1994). Each animal was housed individually in a pen with a covered area $(6 \mathrm{~m} \times 7$ $\mathrm{m})$ and an uncovered area $(12 \mathrm{~m} \times 7 \mathrm{~m})$. The covered area contained a bedded pack comprising rubber mats $(3.6 \mathrm{~m} \times 2.4 \mathrm{~m}, 19 \mathrm{~mm}$ thick; Animat, Animat Inc., Saint-Elie d'Orford, Quebec, Canada) covered in $15 \mathrm{~cm}$ of rice hulls. Each animal had free access to water and was fed a TMR consisting of $16 \%$ almond hulls, $5 \%$ commercial dry cow pellets (Associated Feed and Supply Co., Turlock, CA), $26 \%$ alfalfa hay, and $53 \%$ oats twice daily at 1030 and $1900 \mathrm{~h}$.

Behavioral Observations. Lying and standing times were recorded using the same equipment and behavioral definitions used in experiment 1 . Two cameras and 2 red lights (2.7 to $3.9 \mathrm{~m}$ above the pen) were used to record the lying behavior in each of the 4 pens, and each camera was set to continuously record at low quality and 10 frames/s. Onset Pendant G data loggers $(64 \mathrm{~K})$ were set to record the $\mathrm{y}$ - and z-axis at a 6 -s interval until the data loggers were full, approximately $2.2 \mathrm{~d}$. The $\mathrm{x}$-axis was excluded because, based on the results from experiment 1 , we had determined that this information was not needed.

\section{Onset Loggers}

The data loggers were placed in a durable fabric pouch and attached on either the lateral side of the hind leg above the metatarsophalangeal joint (experi- 
ment 1 ) or the medial side of the hind leg above the metatarsophalangeal joint (experiment 2), with the leg (right or left) balanced across both groups and cows. No pouch was used on 4 animals in experiment 2; instead, the loggers were wrapped in cloth and VetWrap cohesive bandage (3M Products, St. Paul, MN) and placed directly on the leg. Before attaching the logger, 1 to 2 layers of VetWrap were placed around the leg and a thin film of petroleum jelly (Vaseline Intensive Care, Chesebrough Ponds, Greenwich, CT) was spread on the wrap to reduce the possibility of injury caused by the logger rubbing against the leg. The loggers were positioned on the leg such that the $\mathrm{x}$-axis was parallel to the ground pointing in the cranial direction, the yaxis was perpendicular to the ground pointing toward the cow's back (dorsal direction), and the z-axis was parallel to the ground pointing toward the midplane. The pouch was then wrapped with VetWrap until it was secure, using approximately $75 \%$ of a roll.

\section{Handling Output from Onset Pendant G Data Loggers}

The data collected by the loggers were downloaded using Onset HOBOware Software (Onset Computer Corporation) and exported to Microsoft Excel. From this data set, we examined 4 sampling intervals: 6,30 , 60 , and $300 \mathrm{~s}$. The latter 3 sampling intervals $(30,60$, and $300 \mathrm{~s}$ ) were created by keeping every fifth, tenth, or 50th recording, respectively.

The Onset Pendant $\mathrm{G}$ data logger recorded the $g$ force on the $\mathrm{x}, \mathrm{y}$, and z-axes on a scale of -3.2 to 3.2. In addition to $g$ forces, the logger output can be considered in degrees of tilt. The user makes this choice; we opted for $g$ forces. A constant (3.2) was added to all values to make all $g$ forces positive (new range: 0 to 6.4) to facilitate data handling. The cut-off values used to categorize logger readings as a specific behavior (lying vs. standing; lying on the left side vs. lying on right side) were determined based on preliminary visual observation from the video recordings. Information from the y-axis was used to evaluate lying $(\geq 2.55)$ and standing $(<2.55)$ behavior, and information from the $\mathrm{z}$-axis was used to determine whether the cow was lying on the right or left side. For example, if the logger was placed on the right leg and the cow was lying down, then a z-axis recording of $<3.025$ indicated lying on the right side and a recording of $\geq 3.025$ indicated lying on the left side. This pattern was reversed if the logger was placed on the left leg.

Several Excel macros were used to modify, correct, and edit data generated by the loggers. Two macros altered the output, making it easier to manipulate. The first macro added a constant 3.2 to the values from $y$ - and z-axis to make all values of $g$ force positive as described above, and the second macro changed these values into sequences of 1s (lying) and 0s (standing). Finally, data were edited with 1 of 3 filters to examine the effect of short, potentially erroneous readings of lying or standing events. These filter macros converted readings (i.e., lying events bordered by standing or vice versa) occurring singly or in consecutive runs of $\leq 2$ or $\leq 6$ to the behavior preceding them. Below, these editing regimens are referred to as 1-, 2-, or 6-event filters. Laterality was taken into account in all cases such that lying on the left followed by lying on the right was counted as a new lying bout. In total, each experiment had 16 data sets: 4 sampling intervals $(6,30,60$, and $300 \mathrm{~s}$ ) and 4 levels of editing (unfiltered or 1-, 2-, or 6 -event filter). From these data sets, a fourth macro was used to calculate average bout length (min/bout), total lying time $(\mathrm{h} / 24 \mathrm{~h})$, time lying on left and right side ( $\mathrm{h} / 24 \mathrm{~h}$ and $\%$ of total lying time), and number of bouts (bouts/24 h) for each cow.

\section{Statistical Analysis}

The 16 data sets/experiment were used to calculate predictability (lying events identified by the logger were also recorded from video), sensitivity (lying events recorded from video were correctly identified by the logger), and specificity (standing events recorded from video were correctly identified by the logger). Overall agreement (both logger and video identify standing and lying) was also calculated.

All lying times are presented on a 24 -h basis to facilitate comparisons with other studies. Estimates of total lying time (h/24 h), number of bouts (bouts/24 h), and percentage time on the left side for each combination of sampling interval and editing regimen were compared with the values generated from video recordings with linear regression (PROC REG in SAS; SAS, 1999). Each experiment was considered separately and 3 parameters (coefficient of determination and whether the slope and intercept differed from 1 and 0 ) were generated from these regressions.

\section{RESULTS}

A practical consideration guided the presentation of our results. Recent work has found that at least 3 d of behavioral information is required to accurately describe the lying time and number of lying bouts on a dairy farm (Ito et al., 2009). The 6-s sampling interval would not allow $3 \mathrm{~d}$ of recording; thus, when equivalent, we emphasized results from the longer sampling intervals. 
Table 2. Predictability, sensitivity, and specificity ${ }^{1}$ calculated for the Onset Pendant G data logger (Onset Computer Corporation, Bourne, MA) set to record at 4 sampling intervals $(6,30,60$, or $300 \mathrm{~s})$, either unfiltered or filtered with a macro, ${ }^{2}$ for experiments 1 and $2^{3}$

\begin{tabular}{|c|c|c|c|c|c|c|c|c|c|c|c|c|}
\hline $\begin{array}{l}\text { Experiment } \\
\text { no. } \\
\text { and sampling } \\
\text { interval }\end{array}$ & \multicolumn{4}{|c|}{ Predictability } & \multicolumn{4}{|c|}{ Sensitivity } & \multicolumn{4}{|c|}{ Specificity } \\
\hline \multicolumn{13}{|l|}{ Experiment 1} \\
\hline $6 \mathrm{~s}$ & 99.9 & 99.9 & 99.9 & 99.9 & 99.3 & 99.8 & 99.9 & 99.8 & 99.8 & 99.9 & 100.0 & 99.9 \\
\hline $30 \mathrm{~s}$ & 99.8 & 99.9 & 99.9 & 99.9 & 99.3 & 99.8 & 99.7 & 99.5 & 99.7 & 99.9 & 99.9 & 99.8 \\
\hline $60 \mathrm{~s}$ & 99.8 & 99.9 & 99.9 & 99.7 & 99.3 & 99.7 & 99.6 & 98.9 & 99.8 & 99.9 & 99.9 & 99.6 \\
\hline $6 \mathrm{~s}$ & 99.6 & 99.7 & 99.7 & 99.7 & 97.6 & 99.2 & 99.4 & 99.5 & 99.4 & 99.8 & 99.9 & 99.9 \\
\hline $30 \mathrm{~s}$ & 99.6 & 99.6 & 99.5 & 99.1 & 97.6 & 99.4 & 99.4 & 98.8 & 99.5 & 99.9 & 99.9 & 99.7 \\
\hline $60 \mathrm{~s}$ & 99.6 & 99.5 & 99.3 & 97.5 & 97.4 & 99.3 & 99.0 & 97.9 & 99.4 & 99.8 & 99.8 & 99.5 \\
\hline $300 \mathrm{~s}$ & 99.7 & 97.1 & 94.5 & 84.7 & 96.2 & 97.1 & 95.3 & 82.3 & 99.0 & 99.3 & 98.9 & 95.5 \\
\hline
\end{tabular}

${ }^{1}$ Predictability $=$ likelihood that a lying event recorded by Onset Pendant G data logger was also recorded by the video; sensitivity $=$ likelihood that a lying event recorded by the continuous video was recorded by the Onset Pendant G data logger; specificity $=$ likelihood that a standing event was recorded by both the logger and the continuous video.

${ }^{2}$ Data were edited with 1 of 3 filters to examine the effect of short, potentially erroneous readings of lying or standing events. These filter macros converted readings (i.e., lying events bordered by standing or vice versa) occurring singly or in consecutive runs of $\leq 2$ or $\leq 6$ to the behavior proceeding them. These editing regimens are referred to as 1-, 2-, or 6-event filters.

${ }^{3}$ Experiment 1 = cows $(\mathrm{n}=12)$ in a freestall bedding system with loggers attached to the lateral side of the hind leg above the metatarsophalangeal joint; experiment $2=$ cows $(n=12)$ in an open bedding system with loggers attached to the medial side of the rear leg above the metatarsophalangeal joint.

Predictability, sensitivity, and specificity for each combination of sampling interval and editing regimen for lying behavior are reported in Table 2. As an example, for each of the 12 cows in each experiment, the logger (30 s, 1-event filter) and video recordings are summarized in Table 3. Similarly, predictability, sensitivity, and specificity were $\geq 98.5 \%$ for lying right and left when the 30- or 60-s sampling interval and 1-event editing regimen were used.

Average total lying time $(\mathrm{h} / 24 \mathrm{~h})$ obtained from video was (mean $\pm \mathrm{SD}) 12.6 \pm 1.5 \mathrm{~h} / 24 \mathrm{~h}$ in experiment 1 and $10.0 \pm 1.9 \mathrm{~h} / 24 \mathrm{~h}$ in experiment 2 . A clear relationship was found between the lying times obtained from video and those recorded by the Onset Pendant G data logger for the 6-, 30-, and 60-s sampling intervals for all levels of editing in both experiments (Figure 1). Removing short standing and lying events with the filters resulted in an accurate estimate of lying time (Table 4; $P>0.05$ for slope $=1$, intercept $=0$ ), particularly in experiment 2 .

The number of bouts (bouts/24 h) obtained from video was (mean $\pm \mathrm{SD}$ ) $11.5 \pm 2.7$ bouts $/ 24 \mathrm{~h}$ in experiment 1 and $15.8 \pm 6.5$ bouts $/ 24 \mathrm{~h}$ in experiment 2 . In both experiments, the 6 -s sampling interval required consecutive recordings of $\leq 6$ to be filtered out to clearly correspond with the values generated from video $\left(\mathrm{R}^{2} \geq\right.$ 0.942 for 6 -event filter; $\mathrm{R}^{2} \leq 0.802$ for all other editing methods at this sampling interval). The $30-$ and 60 -s sampling intervals corresponded with the video recordings when $\leq 2$ lying and standing events were filtered from the data set $\left(R^{2} \geq 0.927\right.$; Figure 2). Despite the positive relationship between the estimates generated with the 60-s sampling interval, any editing resulted in a slope greater than 1 or an intercept significantly greater than 0 in experiment 2 (Table 4). A similar pattern was found with the 300-s sampling interval. In both experiments, the unfiltered estimate at $300 \mathrm{~s}$ had the best relationship $\left(R^{2} \geq 0.915\right)$, but slope or intercept were significantly different from 0 or 1 in experiment 2 (Table 4). Indeed, the number of lying bouts estimated with the 300-s sampling interval and no filtering deviated from the true values by 8.6 and $10.7 \%$ in experiment 1 and 2, respectively. This deviation may be explained, in part, by a relatively high percentage of short $(<300 \mathrm{~s})$ lying and standing bouts (Figure 3; 12 and $34 \%$ of lying and standing bouts were $<300 \mathrm{~s}$ in experiment 1 and 2, respectively). In particular, experiment 2 had considerably more short lying bouts: $1.5 \%$ of lying bouts were $\leq 300 \mathrm{~s}$ in experiment 1 , compared with $23.8 \%$ of lying bouts in experiment 2 .

The percentage time spent lying on the left side (\% of lying time) obtained from video was (mean $\pm \mathrm{SD}$ ) $53.6 \pm 12.5 \%$ in experiment 1 and $49.1 \pm 18.5 \%$ in experiment 2. Considerable variation was found between individuals in this behavior: the range was between 5 and $90 \%$ of lying on the left side. All combinations of sampling and editing the logger information were highly related to values obtained from video $\left(\mathrm{R}^{2} \geq\right.$ 0.987), with 1 exception. The 300-s sampling interval and the 6-event filter had coefficient of determination of 0.737 and 0.801 for experiments 2 and 1 , respectively. As with total lying time, removal of short standing and 
Table 3. Lying and standing events recorded with video and with the Onset Pendant G data logger (Onset Computer Corporation, Bourne, MA) set to record at 30-s intervals and filtered with a macro that converted single readings of lying and standing to the behavior that preceded them ${ }^{1,2}$

\begin{tabular}{lcccc}
\hline $\begin{array}{l}\text { Experiment no. } \\
\text { and cow no. }\end{array}$ & $\begin{array}{c}\text { Video }=\text { lying, } \\
\text { logger }=\text { lying }\end{array}$ & $\begin{array}{c}\text { Video = lying, } \\
\text { logger }=\text { standing }\end{array}$ & $\begin{array}{c}\text { Video = standing, } \\
\text { logger }=\text { lying }{ }^{5}\end{array}$ & $\begin{array}{c}\text { Video }=\text { standing, } \\
\text { logger }=\text { standing }^{6}\end{array}$ \\
\hline Experiment 1 & & & & \\
1 & 1,890 & 0 & 5 & 6,504 \\
2 & 1,893 & 5 & 7 & 6,224 \\
3 & 2,500 & 3 & 9 & 5,836 \\
4 & 2,234 & 1 & 3 & 6,118 \\
5 & 2,355 & 5 & 3 & 6,007 \\
6 & 2,307 & 2 & 2 & 6,018 \\
7 & 2,344 & 5 & 3 & 6,015 \\
8 & 2,435 & 4 & 5 & 5,998 \\
9 & 2,413 & 4 & 4 & 5,822 \\
10 & 1,983 & 3 & 1 & 6,422 \\
11 & 1,737 & 1 & 5 & 6,747 \\
12 & 2,270 & 1 & & 6,150 \\
Experiment & & & 1 & \\
13 & 2,894 & 3 & 24 & 9,562 \\
14 & 3,081 & 20 & 13 & 9,619 \\
15 & 2,414 & 15 & 11 & 10,106 \\
16 & 2,268 & 3 & 12 & 10,128 \\
17 & 2,605 & 4 & 20 & 10,025 \\
18 & 2,452 & 16 & 4 & 8,020 \\
19 & 2,881 & 3 & 27 & 11,069 \\
20 & 1,349 & 9 & 15 & 10,610 \\
21 & 2,210 & 9 & 5 & 9,730 \\
22 & 2,975 & 6 & 11 & 9,140 \\
23 & 2,836 & 1 & 25 & 9,445 \\
24 & 2,942 & 22 & & 5 \\
\hline
\end{tabular}

${ }^{1}$ Experiment 1 = cows $(\mathrm{n}=12)$ in a freestall bedding system with loggers attached to the lateral side of the hind leg above the metatarsophalangeal joint; experiment $2=$ cows $(n=12)$ in an open bedding system with loggers attached to the medial side of the rear leg above the metatarsophalangeal joint.

${ }^{2}$ Recordings began at the beginning of the first lying event, resulting in unequal total recording times for experiments 1 and 2 (approximately 1.5 and $2.2 \mathrm{~d}$, respectively).

${ }^{3}$ Recordings (n) when both the Onset data loggers and the video detected a lying event.

${ }^{4}$ Recordings (n) when only the video detected a lying event.

${ }^{5}$ Recordings (n) when only the Onset data loggers detected a lying event.

${ }^{6}$ Recordings (n) when neither the Onset data loggers nor video detected a lying event (i.e., standing).

lying events from data sets sampled at $\leq 60 \mathrm{~s}$ was required for the slope and intercept of this relationship to equal 1 and 0 , respectively (Table 4).

In summary, to recommend a sampling regimen and appropriate filter for a given behavior, we suggest that 3 criteria must be met: no statistical difference $(P>$ $0.05)$ from 1 and 0 for slope and intercept, respectively, and $\mathrm{R}^{2} \geq 0.90$ in both experiments. The combinations of sampling interval and filters that meet these 3 criteria are summarized for each behavior in Table 4 .

\section{DISCUSSION}

The Onset Pendant G data logger accurately measured lying time, laterality of lying behavior, and number of lying bouts. From this information, the average bout length can also be calculated. Both the sampling interval and editing method affected the accuracy of the information generated by Onset Pendant G data logger.
In the current experiments, cows spent between 5.2 and $14.4 \mathrm{~h} / 24 \mathrm{~h}$ lying down; these values are within the range reported in the literature (Tucker et al., 2004b). The relationship between estimates of lying time and the true values from video recordings were excellent at all 4 sampling intervals. This is likely because the relatively short sampling intervals were more than what is required to detect a behavior in which animals spend a considerable amount of time engaged (Martin and Bateson, 2007) and these results agree with previous work with beef cattle (Mitlöhner et al., 2001). However, an interaction was found between sampling interval and filtering method on the accuracy of the estimate of lying time. For all sampling intervals of $\leq 60 \mathrm{~s}$, short, potentially erroneous readings of lying and standing events need to be removed from the data set to generate a 1:1 relationship with true values of lying time. However, when lying time was estimated by sampling every $300 \mathrm{~s}$, correcting short standing or lying bouts reduced the relationship with true lying time, particu- 
larly in experiment 2 . This is likely because a relatively high proportion of short lying bouts $(23.8 \%<300$ s) was found in this experiment and deleting these values reduced the accuracy of the estimate of lying time.

Cows lay down, on average, 8 to 29 times/24 h. The number of lying bouts estimated by the logger with the 6- and 30-s sampling intervals was positively related to values generated from video recordings when short lying and standing events were removed. Although estimates of lying bouts collected with the 60- and 300-s sampling intervals were related to values from video, a consistent 1:1 relationship with true values was not found. For example, the number of lying bouts estimated by the logger deviated from the true value by 9 and $11 \%$ in experiments 1 and 2 when the 300-s unfiltered regimen was used. This is likely because short lying and standing bouts were missed at this longer sampling interval. Thus, these results indicate that using the 6 - or $30-\mathrm{s}$ sampling interval and a 6 -event or 1- or 2-event editing regimen, respectively, is recommended when measuring the number of lying bouts with the Onset Pendant G data loggers.

In addition to influencing the appropriate sampling and filtering method, the structure of lying bouts, in particular the proportion of short lying bouts, may provide some insight into cow comfort. We found a

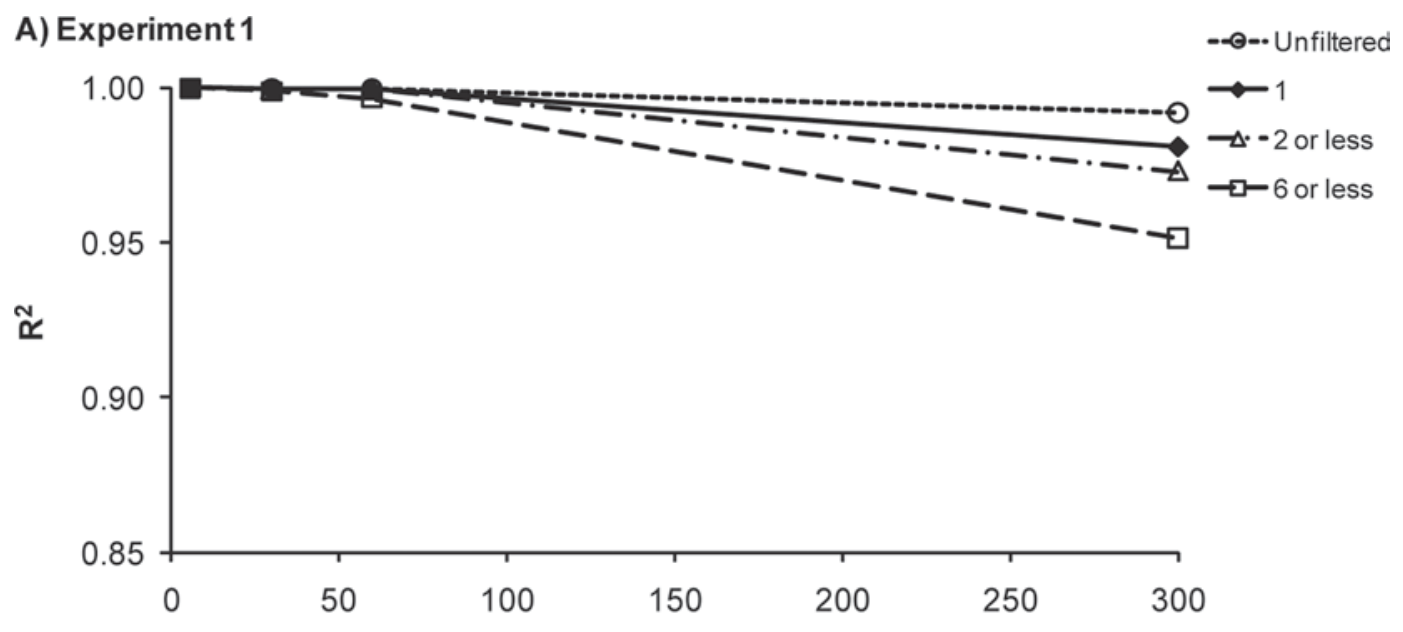

B) Experiment 2

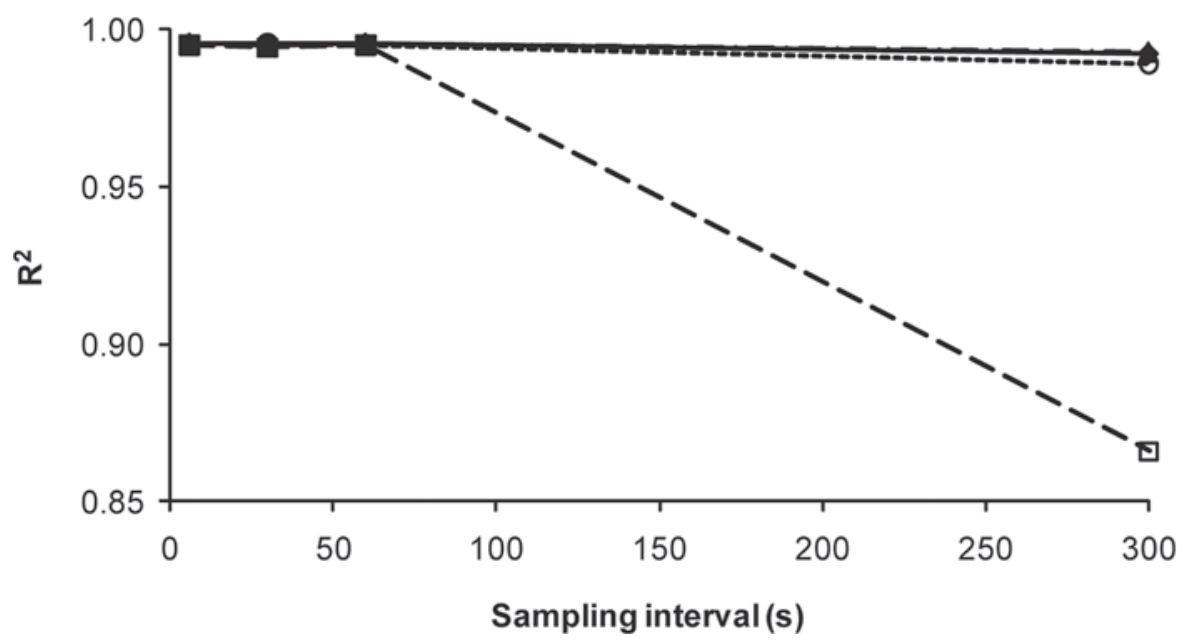

Figure 1. Relationship between total lying time $(\mathrm{h} / 24 \mathrm{~h})$ obtained from video recordings and estimates obtained from an Onset Pendant $\mathrm{G}$ data logger (Onset Computer Corporation, Bourne, MA) attached to A) the lateral side of the hind leg for 12 dairy cows housed in a freestall barn (experiment 1) and B) the medial side of the hind leg for 12 dairy cows housed in an open bedding system (experiment 2). Four sampling intervals were examined $(6,30,60$, and $300 \mathrm{~s})$. To evaluate the effect of short, possibly erroneous readings, these data either remained unfiltered or were edited with a macro that converted readings of lying and standing that occurred singly or in runs of $\leq 2$ or $\leq 6$ to the behavior that preceded them. 
Table 4. Filtering ${ }^{1}$ required to generate a relationship between true value ${ }^{2}$ of behavior (as measured by video) and measures taken from a data logger ${ }^{3}$

\begin{tabular}{|c|c|c|c|}
\hline $\begin{array}{l}\text { Item and } \\
\text { sampling interval }\end{array}$ & Experiment 1 & Experiment 2 & $\begin{array}{l}\text { Recommended } \\
\text { filtering }\end{array}$ \\
\hline \multicolumn{4}{|l|}{ Total lying time } \\
\hline $6 \mathrm{~s}$ & Unfiltered, 1, 2, 6 & $1,2,6$ & $1,2,6$ \\
\hline $30 \mathrm{~s}$ & Unfiltered, $1,2,6$ & $1,2,6$ & $1,2,6$ \\
\hline $60 \mathrm{~s}$ & Unfiltered, 1, 2, 6 & $1,2,6$ & $1,2,6$ \\
\hline $300 \mathrm{~s}$ & Unfiltered, 1,6 & Unfiltered, 1,6 & Unfiltered, 1 \\
\hline \multicolumn{4}{|l|}{ Lying bouts (n) } \\
\hline $6 \mathrm{~s}$ & Unfiltered, $1,2,6$ & Unfiltered, 1, 2, 6 & 6 \\
\hline $30 \mathrm{~s}$ & Unfiltered, $1,2,6$ & Unfiltered, 1, 2 & 1,2 \\
\hline $60 \mathrm{~s}$ & Unfiltered, 1, 2, 6 & Unfiltered & - \\
\hline $300 \mathrm{~s}$ & Unfiltered, 1,2 & - & - \\
\hline \multicolumn{4}{|c|}{ Time lying on left side (\%) } \\
\hline $6 \mathrm{~s}$ & 2,6 & $1,2,6$ & 2,6 \\
\hline $30 \mathrm{~s}$ & $1,2,6$ & $1,2,6$ & $1,2,6$ \\
\hline $60 \mathrm{~s}$ & Unfiltered, $1,2,6$ & 1,2 & 1,2 \\
\hline $300 \mathrm{~s}$ & Unfiltered, $1,2,6$ & Unfiltered, $1,2,6$ & Unfiltered, 1, 2 \\
\hline
\end{tabular}

${ }^{1}$ Four filtering regimens were considered to evaluate the effect of short, possibly erroneous readings from the logger: unfiltered or edited with a macro that converted 1,2 , or 6 consecutive readings of lying and standing to the behavior that preceded them at each of the 4 sampling intervals $(6,30,60$, and $300 \mathrm{~s})$.

${ }^{2}$ In experiments 1 and 2 , no statistical difference $(P>0.05)$ was found from 0 and 1 for intercept and slope, respectively, for the relationship between video and logger output. The recommended combination is where the slope and intercept were not statistically different $(P>0.05)$ from 1 and 0 , respectively, and $\mathrm{R}^{2} \geq 0.90$ for experiments 1 and 2 .

${ }^{3}$ Experiment $1=$ cows $(n=12)$ in a freestall bedding system with loggers attached to the lateral side of the hind leg above the metatarsophalangeal joint; experiment $2=$ cows $(n=12)$ in an open bedding system with loggers attached to the medial side of the rear leg above the metatarsophalangeal joint.

relatively high proportion of short lying bouts $(23.8 \%$ of lying bouts $<300 \mathrm{~s}$ ) in experiment 2 compared with experiment 1 ( $1.5 \%$ of lying bouts $<300 \mathrm{~s})$. Several differences existed between our experiments, including housing type (freestalls in experiment 1 vs. bedded pack in experiment 2), group size (24 cows vs. single housing), stage of lactation (lactating vs. dry), and logger placement (lateral vs. medial side of the leg). Although the current work was not designed to explicitly test these effects, others have reported potential effects of housing system on bout length. For instance, when cows are kept in deep-bedded straw, almost $40 \%$ of lying bouts were $<15$ min compared with approximately $20 \%$ of lying bouts when cows were housed in tie-stalls (Krohn and Munksgaard, 1993), perhaps because of differences in comfort or because of social disturbance from other cows within the group. Dechamps et al. (1989) found no difference in the proportion of lying bouts $<15 \mathrm{~min}$ for cattle housed in tie-stalls and freestalls; however, animals were restrained in both systems by the device used to measure lying behavior. The proportion of short lying bouts in experiment 1 was closer to values reported for cows housed in freestalls ( 7.5 vs. $5.2 \%$ lying bouts $<10 \mathrm{~min}$ in the current experiment and Tucker et al., 2009, respectively). Most studies of lying behavior do not report bout structure (except Nicks et al., 1988, and Cook et al., 2004), but the proportion of short lying bouts may be easier to measure with data loggers and may be used as an indicator of comfort, particularly of individually housed cows, in the future.

This is the first work to demonstrate that a data logger can accurately describe the laterality of lying behavior. As with total lying time, all sampling intervals accurately measured time on the left side once short standing and lying events were removed. Considerable variation was also found in the parameter: one cow spent $5 \%$ of lying time on the left side, whereas another individual spent $90 \%$ of lying time on the left side. In the approximately 10 studies of laterality of lying behavior in cattle, a portion have found that cows spend more time on the left side whereas others report no difference between the left and right (reviewed in Tucker et al., 2009). Physiological state, particularly late gestation and cannulation, influence the laterality of lying behavior (Arave and Walters, 1980; Grant et al., 1990; Forsberg et al., 2008), suggesting that pronounced laterality may indicate discomfort. We have only begun to understand the role of laterality as an indicator of cow comfort, and the ability of the Onset Pendant $\mathrm{G}$ data logger to accurately measure this aspect of lying behavior may facilitate future studies of this topic.

Based on the results from the current experiments, the Onset Pendant G data logger accurately measured all aspects of lying behavior when the sampling interval was $\leq 30 \mathrm{~s}$ and short readings of lying and standing 


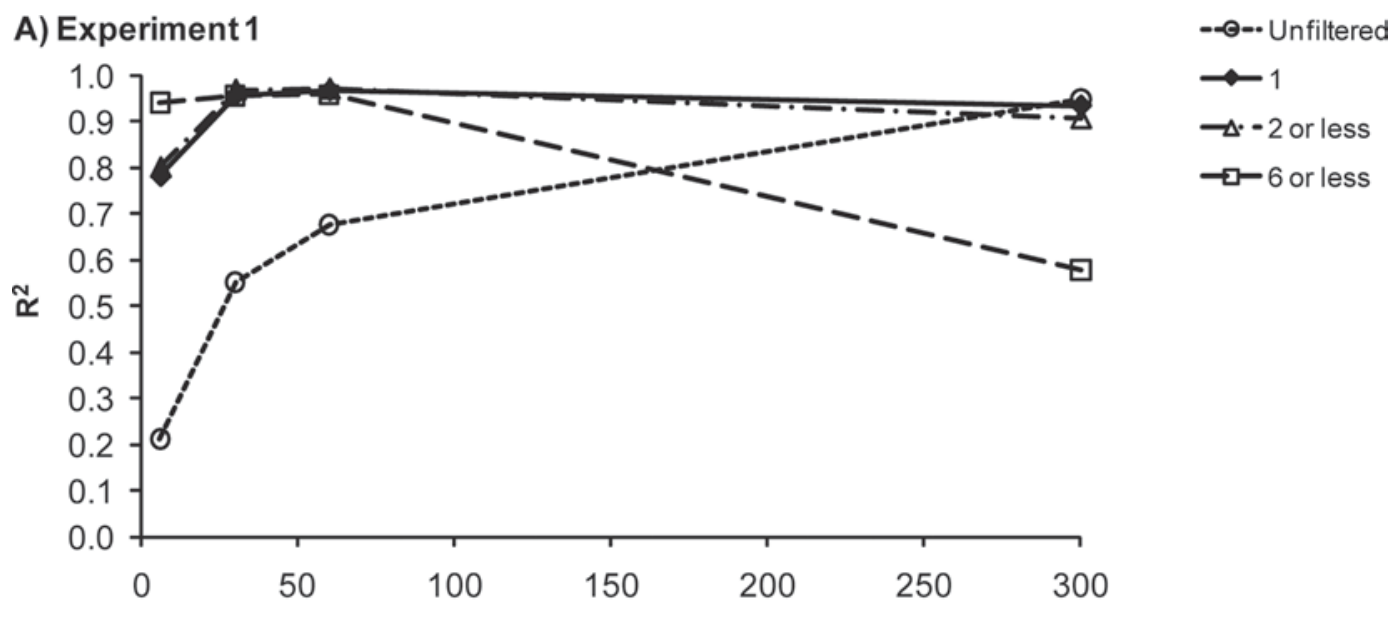

\section{B) Experiment 2}

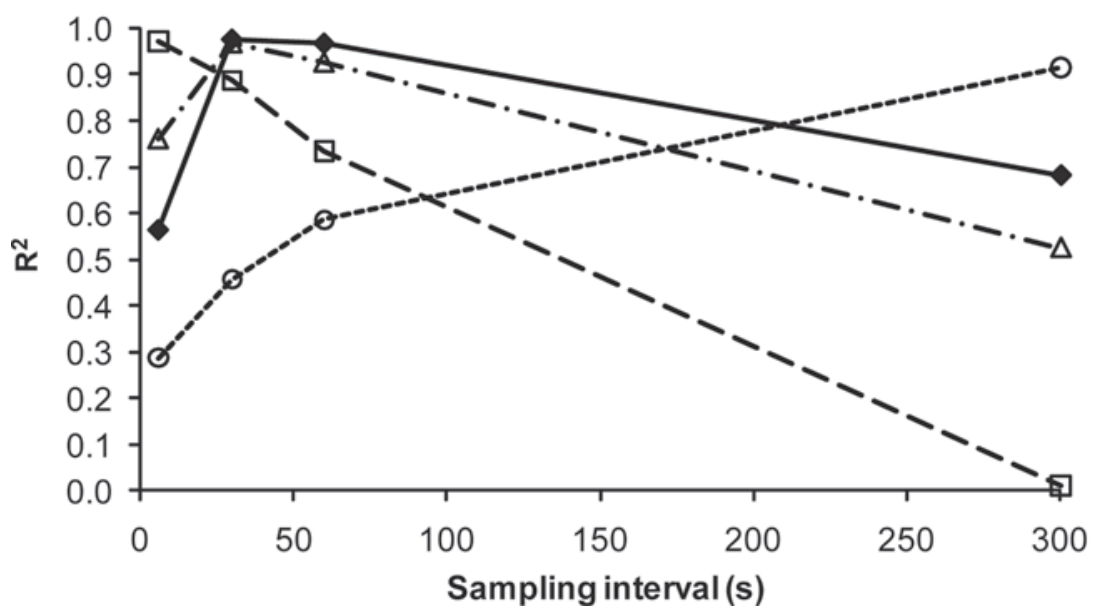

Figure 2. Relationship between the number of bouts $/ 24 \mathrm{~h}$ obtained from video recordings and the estimates obtained with an Onset Pendant G data logger (Onset Computer Corporation, Bourne, MA) attached to A) the lateral side of the hind leg for 12 dairy cows housed in a freestall barn (experiment 1) and B) the medial side of the hind leg for 12 dairy cows housed in a open bedding system (experiment 2). Four sampling intervals were examined $(6,30,60$, and $300 \mathrm{~s})$. To evaluate the effect of short, possibly erroneous readings, these data remained unfiltered or were edited with a macro that converted readings of lying and standing that occurred singly or in runs of $\leq 2$ or $\leq 6$ to the behavior that preceded them.

were filtered from the data set. When recording at 30-s intervals on the $\mathrm{y}$ - and z-axes, the recording capacity is approximately $11 \mathrm{~d}$; this is more than the $3 \mathrm{~d}$ of information required to accurately estimate lying behavior on commercial farms (Ito et al., 2009). If the recording time is set to a 1-s interval on 3 axes, as may be needed for measurement of motion, the recording time falls to 6 h. Other loggers, such as Tinytag Plus (Gemini Data Loggers), face similar memory limitations (O'Driscoll et al., 2008). Indeed, loggers measuring motion need to have a larger amount of internal memory or transmit data to a receiver (e.g., Scheibe and Gromann, 2006).

\section{CONCLUSIONS}

The Onset Pendant G data logger accurately measured lying time, number of lying bouts, and laterality of lying behavior when the sampling interval was $\leq 30$ $\mathrm{s}$ and short readings of lying and standing were filtered from the data set. Less frequent sampling (e.g., $300 \mathrm{~s}$ ) is appropriate for estimating lying time. Shorter intervals between samples (every $\leq 30 \mathrm{~s}$ ) are required to accurately measure the number of lying bouts, particularly if lying and standing bouts are very short. Automated measurement of lying time, number of lying bouts, bout structure, and laterality of lying behavior will reduce labor requirements for this type of research and improve our biological understanding of cow comfort.

\section{ACKNOWLEDGMENTS}

We thank University of California Davis dairy farm manager Doug Gisi and the interns at the dairy farm 


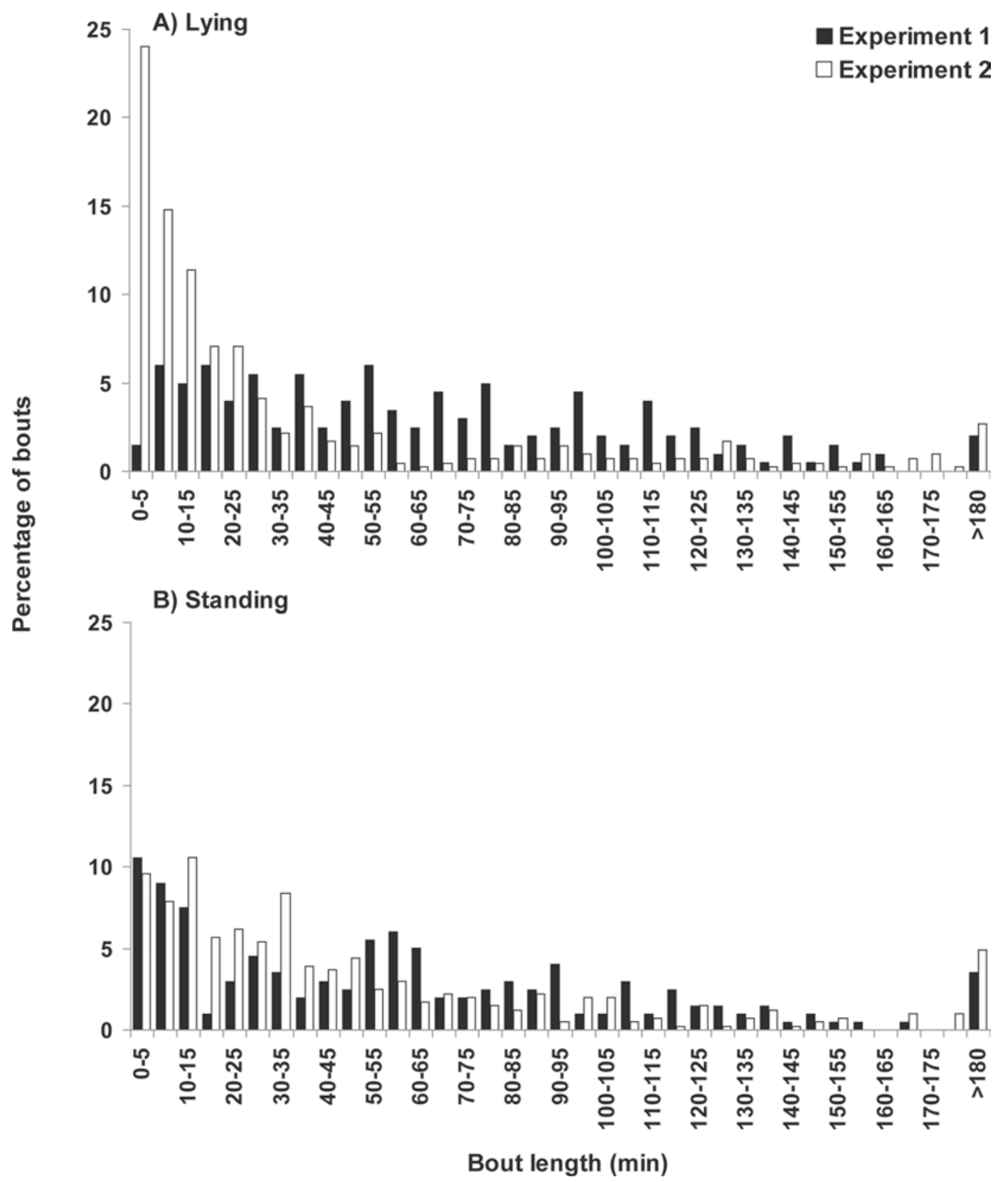

Figure 3. Distribution of A) lying and B) standing bout length for 24 dairy cows in experiments 1 and 2 . Experiment $1=$ cows $(\mathrm{n}=12)$ in a freestall bedding system with loggers attached to the lateral side of the hind leg above the metatarsophalangeal joint; experiment $2=$ cows ( $\mathrm{n}$ $=12$ ) in an open bedding system with loggers attached to the medial side of the rear leg above the metatarsophalangeal joint.

for their help throughout the experiments. We are also grateful to Nadège Krebs (UC Davis) and Thomas Grubmüller (BOKU) for their help with experiment 1 and Amanda Grout and Amélie Legrand (UC Davis) for their help with experiment 2. Dan Weary and Lisanne Steuenberg (University of British Columbia) identified this application of the Onset Logger and suggested the initial idea for this work. Kiyomi Ito (University of British Columbia) kindly provided valuable comments on a draft of this manuscript.

\section{REFERENCES}

Arave, C. W., and J. L. Walters. 1980. Factors affecting lying behavior and stall utilization of dairy cattle. Appl. Anim. Ethol. 6:369-376.

Champion, R. A., S. M. Rutter, and P. D. Penning. 1997. An automatic system to monitor lying, standing and walking behaviour of grazing animals. Appl. Anim. Behav. Sci. 54:291-305.

Chapinal, N., A. M. de Passillé, D. M. Weary, M. A. G. von Keyserlingk, and J. Rushen. 2009. Using gait score, walking speed, and lying behavior to detect hoof lesions in dairy cows. J. Dairy Sci. 92:4365-4374. 
Cook, N. B., T. B. Bennett, and K. V. Nordlund. 2004. Effect of free stall surface on daily activity patterns in dairy cows with relevance to lameness prevalence. J. Dairy Sci. 87:2912-2922.

Darr, M., and W. Epperson. 2009. Embedded sensor technology for real time determination of animal lying time. Comput. Electron. Agric. 66:106-111.

Dechamps, P., B. Nicks, B. Canart, M. Gielen, and L. Istasse. 1989. A note on resting behaviour of cows before and after calving in two different housing systems. Appl. Anim. Behav. Sci. 23:99-105.

Ferguson, J. D., D. T. Galligan, and N. Thomsen. 1994. Principal descriptors of body condition score in Holstein cows. J. Dairy Sci. 77:2695-2703.

Forsberg, A.-M., G. Pettersson, T. Ljungberg, and K. SvennerstenSjaunja. 2008. A brief note about cow lying behaviour-Do cows choose left and right lying side equally? Appl. Anim. Behav. Sci. 114:32-36.

Fregonesi, J. A., D. M. Veira, M. A. G. von Keyserlingk, and D. M. Weary. 2007. Effects of bedding quality on lying behavior of dairy cows. J. Dairy Sci. 90:5468-5472.

Grant, R. J., V. F. Colenbrander, and J. L. Albright. 1990. Effect of particle size of forage and rumen cannulation upon chewing activity and laterality in dairy cows. J. Dairy Sci. 73:3158-3164.

Grubmüller, T. 2008. Effect of dataloggers on the lying behaviour of dairy cows. Diploma thesis. University of Natural Resources and Applied Life Sciences, Vienna, Austria.

Haley, D. B., A. M. de Passillé, and J. Rushen. 2001. Assessing cow comfort: Effects of two floor types and two tie stall designs on the behaviour of lactating dairy cows. Appl. Anim. Behav. Sci. 71:105-117.

Ito, K., D. M. Weary, and M. A. G. von Keyserlingk. 2009. Lying behavior: Assessing within- and between-herd variation in free-stallhoused dairy cows. J. Dairy Sci. 92:4412-4420.

Krohn, C. C., and L. Munksgaard. 1993. Behaviour of dairy cows kept in extensive (loose housing/pasture) or intensive (tie stall) environments II. Lying and lying-down behaviour. Appl. Anim. Behav. Sci. 37:1-16.

Martin, P., and P. Bateson. 2007. Measuring Behaviour: An Introductory Guide. Cambridge University Press, Cambridge, UK.

Martiskainen, P., M. Järvinen, J.-P. Skön, J. Tiirikainen, M. Kolehmainen, and J. Mononen. 2009. Cow behaviour pattern recognition using a three-dimensional accelerometer and support vector machines. Appl. Anim. Behav. Sci. 119:32-38.

McGowan, J. E., C. R. Burke, and J. G. Jago. 2007. Validation of a technology for objectively measuring behaviour in dairy cows and its application for oestrous detection. NZ Soc. Anim. Prod. 67:136-142.
Mitlöhner, F. M., J. L. Morrow-Tesch, S. C. Wilson, J. W. Dailey, and J. J. McGlone. 2001. Behavioral sampling techniques for feedlot cattle. J. Anim. Sci. 79:1189-1193.

Müller, R., and L. Schrader. 2003. A new method to measure behavioural activity levels in dairy cows. Appl. Anim. Behav. Sci. 83:247-258.

Nicks, B., P. Dechamps, B. Canart, and L. Istasse. 1988. Resting behaviour of Belgian White-Blue and Friesian fattening bulls in a tie-stall barn. Appl. Anim. Behav. Sci. 21:259-266.

O'Driscoll, K., L. Boyle, and A. Hanlon. 2008. A brief note on the validation of a system for recording lying behaviour in dairy cows. Appl. Anim. Behav. Sci. 111:195-200.

Robert, B., B. J. White, D. G. Renter, and R. L. Larson. 2009. Evaluation of three-dimensional accelerometers to monitor and classify behavior patterns in cattle. Comput. Electron. Agric. 67:80-84.

SAS. 1999. User's Guide: Statistics. Version 9.1 ed. SAS Inst. Inc. Cary, NC.

Scheibe, K. M., and C. Gromann. 2006. Application testing of a new three-dimensional acceleration measuring system with wireless data transfer (WAS) for behavior analysis. Behav. Res. Methods $38: 427-433$.

Trénel, P., M. B. Jensen, E. L. Decker, and F. Skjøth. 2009. Technical note: Quantifying and characterizing behavior in dairy calves using the IceTag automatic recording device. J. Dairy Sci. 92:33973401.

Tucker, C. B., N. R. Cox, D. M. Weary, and M. Špinka. 2009. Laterality of lying behaviour in dairy cattle. Appl. Anim. Behav. Sci. 120:125-131.

Tucker, C. B., and D. M. Weary. 2004. Bedding on geotextile mattresses: How much is needed to improve cow comfort? J. Dairy Sci. 87:2889-2895.

Tucker, C. B., D. M. Weary, and D. Fraser. 2004a. Free-stall dimensions: Effects on preference and stall usage. J. Dairy Sci. 87:1208 1216.

Tucker, C. B., D. M. Weary, J. Rushen, and A. M. de Passillé. 2004b. Designing better environments for cattle to rest. Pages 39-53 in Adv. Dairy Technol. Vol. 16. J. Kennelly, ed. Univ. Alberta, Red Deer, Alberta, Canada.

Watanabe, N., S. Sakanoue, K. Kawamura, and T. Kozakai. 2008. Development of an automatic classification system for eating, ruminating and resting behavior of cattle using an accelerometer. Grassl. Sci. 54:231-237.

White, B. J., J. F. Coetzee, D. G. Renter, A. H. Babcock, D. U. Thomson, and D. Andresen. 2008. Evaluation of two-dimensional accelerometers to monitor behavior of beef calves after castration. Am. J. Vet. Res. 69:1005-1012. 